\title{
Disposition Domain
}

National Cancer Institute

\section{Source}

National Cancer Institute. Disposition Domain. NCI Thesaurus. Code C49576.

A subject domain utilized for the submission of information encompassing and representing data, vocabulary or records related to disposition. 